\title{
Is China's Equipment Manufacturing Export Carbon Emissions Decoupled from Export Growth?
}

\author{
Qingbo Huang ${ }^{1}$, Xinxin $\mathrm{Xia}^{1}$, Xuehan Liang ${ }^{1}$, Ye $\mathrm{Liu}^{2}$, Yan $\mathrm{Li}^{3 *}$ \\ ${ }^{1}$ School of Maritime Economics and Management, Dalian Maritime University, Dalian 116026, China \\ ${ }^{2}$ Trade and Economic Management School, Huzhou Vocational and Technical College, Huzhou 313099, China \\ ${ }^{3}$ School of Maritime Economics and Management, Dalian Maritime University, Dalian 116026, China
}

Received: 14 February 2021

Accepted: 17 June 2021

\begin{abstract}
The equipment manufacturing industry is not only a high-carbon industry, but also an important export industry in China. There is a close relationship between the export growth of China's equipment manufacturing industry and its carbon emissions. Based on this, this paper focuses on the equipment manufacturing industry, and establishes a Tapio model to combine the decoupling theory with export carbon emissions. Meanwhile, the relative advantages and disadvantages of the eight decoupling modes are evaluated and determined. Then, the decoupling elasticity index and the decoupling grade index are used to analyze the carbon emissions of China's equipment manufacturing industry and its seven sub-sectors. The study implies that, from 2000 to 2018, the relationship between the overall carbon emissions of the equipment manufacturing industry and export growth was decoupling, and most of the sub-sectors were basically in the state of strong decoupling or weak decoupling. Therefore, the two decoupling optimization paths, which are increasing economic growth and decreasing energy consumption, are designed here to further improve the decoupling effect between the export growth of China's equipment manufacturing industry and its carbon emissions.
\end{abstract}

Keywords: equipment manufacturing, export carbon emissions, export growth, decoupling elasticity index, decoupling level index

\section{Introduction}

Since China's accession to the WTO in 2001, with the total economic volume and export trade grown rapidly, the demand for energy and raw materials has

*e-mail: lilyyan@dlmu.edu.cn continued to increase, resulting in a continuous increase in carbon emissions [1]. On the one hand, China's rapidly increasing carbon emissions have attracted widespread attention in the world, and the pressure to reduce carbon emissions is increasing day by day [2]. On the other hand, in order to realize the sustained, rapid and healthy development of China's economy, it is necessary for China to properly solve the problems of high carbon emissions. Therefore, to calculate the 
relationship between China's export carbon emissions and export growth reasonably will provide immense help to develop the low-carbon economy and promote export transformation [3]. The export of equipment manufacturing industry is an important part of China's foreign trade. The total exports of China's equipment manufacturing industry increased from US $\$ 112.48$ billion in 2000 to US\$1344.49 billion in 2018, and the equipment manufacturing industry's share of China's total exports of goods increased from $45.1 \%$ to $54.2 \%{ }^{1}$.

Therefore, we focus on the equipment manufacturing industry, combine the decoupling theory with export carbon emissions to construct the Tapio model, and evaluate and analyze the pros and cons of the eight decoupling modes, which will help to comprehensively study the decoupling status of China's equipment manufacturing industry from 2000 to 2018.

\section{Literature Review}

Previous studies have fully analyzed the relationship between export trade and carbon emissions, and with the supplement of the decoupling theory, research on the decoupling effect of export growth and carbon emissions has gradually been enriched.

Export trade is closely related to carbon emissions. $30 \%$ of China's carbon emissions are caused by exports [4], of which carbon emissions from exports to the United States account for $1 / 3$ of total exports [5]. Qi and Guan [6] calculated China's GDP, export trade volume, and carbon emissions caused by energy consumption from 1991 to 2013, and analyzed that China's export trade is the main factor for increasing carbon emissions, but GDP growth does not always lead to an increase in carbon emissions. This shows that China's carbon emissions and economic growth have been decoupled to a certain extent. Therefore, they put forward policy recommendations from the perspective of the carbon emission reduction of economic development and trade increasing. Du and Zhang [7] based on the comparable input-output table, using structural decomposition analysis method to study the growth and driving factors of China's export trade embodied carbon emissions, and concluded that China's export trade has a huge amount of carbon emissions, and the growth of total exports is the main factor leading to the growth of China's export trade embodied carbon emissions, but the role of improved export structure in suppressing the increase in carbon emissions is very limited, therefore, it is necessary to further increase the upgrading of export commodities. Zhang and Jiang [8] based on the quantitative analysis of Shandong Province's data from 1984 to 2008, concluded that export trade is the Granger cause of Shandong's carbon emissions and

The author calculated based on data from UN Comtrade and China Statistical Yearbook. economic growth, and economic growth is not the cause of carbon emissions. This conclusion confirms that the relationship between carbon emissions and exports is closer than GDP. Zhang et al. [9] studied the drivers of carbon emissions in China, and the results show that economic growth has a positive effect on carbon emissions. Sun and Zang [10] calculated the energy consumption and environmental pollution caused by export trade between 2002 and 2006 by establishing China's energy-economic input-output model. The results show that China's growing exports are carrying more and more energy consumption and the emission of greenhouse gas and atmospheric pollutants. Deng and Song [11] found that through the analysis of panel data, FDI is conducive to the improvement of China's environmental quality, while foreign trade has worsened our environment. "Pollution Refuge" hypothesis has been confirmed in China. Shui and Harriss [12] believed that China's carbon leakage and carbon exports led to an increase of China's carbon emissions. Ahmed and Wyckoff [13] used input-output tables to study the embodied carbon emissions in China's import and export trade and found that China's export carbon content in 1997 was significantly higher than its import carbon content.

For a long time, rapid economic growth consumes a lot of resources, which has led to the deterioration of the natural environment. However, with the advancement of science and technology and the continuous improvement of human awareness of environmental protection, in the 1970s and 1980s, developed countries in the West began to experience resource depletion or environmental deterioration, which aroused widespread concern in academia. The Organization for Economic Co-operation and Development (OECD) [14] defined this phenomenon as decoupling as early as 2002, and divided it into two types of absolute decoupling and relative decoupling from the perspective of absolute increment and relative increment. When the environment has improved or remains unchanged, it is an absolute decoupling; while the growth rate of environmental damage is less than the economic growth rate, it is a relative decoupling. "Decoupling" means cutting off the close link between environmental pollution and economic growth.

Subsequently, Vehmas et al. [15] combined decoupling and coupling, thinking that the latter may also appear in the process of economic development, and proposed a decoupling index six-point method: strong decoupling, weak decoupling, degeneration fixed decoupling, strong coupling, weak coupling and expansion coupling. Tapio [16] on the basis of the existing decoupling index analysis method, further introduced the elastic algorithm, and used the definition of negative decoupling instead of coupling in the division, adding two types of expansion coupling and degeneration coupling. And the six-point method is expanded to an eight-point method. Lu et al. $[17,18]$ 
based on the IPAT ${ }^{2}$ model to put forward the concept of the threshold value of the annual reduction rate of environmental load per unit GDP, and then in the basis of this threshold value concept to quantitatively study economic growth and environmental load, deduced the resource decoupling index and emission decoupling index, and the degree of decoupling is divided into absolute decoupling, relative decoupling and coupling. Zhu et al. [19] used the IPAT model to predict the midand long-term energy carbon emissions and peak years of Shanxi Province. The results show that, under the current energy and structural status of Shanxi Province, compared with renewable energy annual replacement rate, annual GDP growth rate and annual energy saving rate have a more significant impact on Shanxi province's medium and long-term carbon emissions.

Applied research on decoupling theory is becoming increasingly common. Che et al. [20] calculated the decoupling status between coal utilization efficiency and economic growth, and have reached the conclusion that most regions of China have entered an absolute decoupling state, and the decoupling degree difference between regions is gradually narrowing. Wan and Wang [21], from an industrial perspective, used the 15-year development data of China's equipment manufacturing industry as a research object, proving that China's equipment manufacturing industry's carbon emissions and economic growth generally show a weak decoupling relationship, and the decoupling situation of each subsector industry is quite different. Fan and $\mathrm{Wu}$ [22] used the decoupling theory to analyze the decoupling relationship between China's carbon emissions and economic growth from 2000 to 2011. Studies have shown that the decoupling relationship between the two is weak decoupling, which means the growth range of carbon emissions is smaller than that of economic growth. Using the tapio decoupling theory, Zhou et al. [23] found that the decoupling trend between China's economy and carbon emissions was M-shaped from 1980 to 2015.

In exploring the decoupling effect of economic development and carbon emissions, scholars began to notice the decoupling relationship between export growth and carbon emissions. A large number of existing studies have verified that export trade is an important factor driving China's carbon emissions growth. Xu and Song [24] empirically measured the dynamic relationship between export trade, economic growth and carbon emissions, and concluded that the three variables have a long-term co-integration relationship and that export trade is the Granger cause of

IPAT model was first proposed by Enrlich et al. in 1971, reflecting the relationship between population, economy, technology and environment, that is, the internal relationship between the impact of economic and social development on the natural environment (Impact) and population size (Population), affluence (Affluence), technology level (Technology). the other two. Bai et al. [25] factorized data from major industrial sectors and studied the different effects of export scale, export technology and export structure on China's carbon emissions. On this basis, some scholars began to use the decoupling theory to re-explain the relationship between export growth and export carbon emissions. Liu et al. [26] based on the measurement of China's carbon emissions from 1990 to 2011, and then constructed the Tapio decoupling model to verify the weak decoupling relationship between carbon emissions and exports. The key to achieving decoupling is to reduce the intensity of energy carbon emissions. Zhao et al. [27] also used the Tapio decoupling model to obtain the conclusion that carbon emissions and exports are weakly decoupled, and proposed that improving energy efficiency is an important way to achieve sustainable development of export trade. Hu et al. [28] conducted an empirical analysis of the decoupling relationship between carbon emissions and export growth from the two dimensions of China's 28 industry sectors and tertiary industries. The results show that the relationship of China's foreign trade growth and import and export embodied in carbon emissions is weak decoupling and tends to be stable.

To sum up, it can be seen that the current academic research on decoupling theory is relatively mature, and the methods for calculating the decoupling coefficient are mainly divided into three types: OECD decoupling model, Tapio decoupling model and IPAT model, where Tapio decoupling model is the most widely used and the decoupling status is mainly divided into dichotomy, trisection, six-point and eight-point method. Scholars always use decoupling theory to conduct research on economic growth, resource consumption, and environmental pollution. Many papers have measured and analyzed the decoupling status and influencing factors of carbon emissions from multiple subdivisions such as the overall economic growth, the economic construction of different provinces, and the economic development of different industries.

However, the existing research still has the following two deficiencies. First of all, from the perspective of research methods, foreign scholars' application of decoupling theory is mainly concentrated in the transportation industry, while Chinese scholars mainly use Tapio decoupling theory and its extended theory to study the carbon emissions of various provinces in China. Few studies apply the decoupling theory to the specific sub-industries level. Secondly, from the perspective of research object, the research objects of Chinese and foreign scholars are mainly manufacturing carbon emissions and export trade carbon emissions. There are relatively few studies on the carbon emissions of sub-sectors of the manufacturing industry, and the research is not specific to equipment manufacturing, which makes it difficult to implement export trade carbon emission reduction measures from the perspective of sub-industry. Therefore, by studying the carbon emissions of the export trade of the equipment 
manufacturing industry, this paper combines the decoupling theory with the export carbon emissions to construct the decoupling elasticity index model and the decoupling level index, which means to help deepen the research methods and refine the research perspective.

\section{Current Status of China's Equipment Manufacturing Export Trade}

\section{Overall Scale of China's Equipment Manufacturing Export Trade}

According to China's national economic industry classification, the equipment manufacturing industry is divided into seven major industries, mainly including: metal products industry ${ }^{3}$, general equipment manufacturing industry ${ }^{4}$, special equipment manufacturing industry ${ }^{5}$, transportation equipment manufacturing industry ${ }^{6}$, electrical machinery and equipment manufacturing industry ${ }^{7}$,electronic communications equipment manufacturing industry ${ }^{8}$ and instrumentation, culture and office machinery manufacturing industry9.

Before 2000, the export growth rate of China's equipment manufacturing industry was relatively low. In 2001, China joined the World Trade Organization, and then entered a period of opportunity for equipment manufacturing exports. By 2008, the export value of China's equipment manufacturing industry reached US\$852.411 billion, which was seven times that of

3 Mainly includes: cutting tools, molds, welding rods, containers and other manufacturing industries.

4 Mainly includes: boilers, internal combustion engines, metal cutting machine tools, pumps, fans, compressors, refrigeration equipment, valves, bearings, hydraulic parts, castings and forgings and other manufacturing industries.

5 Mainly includes: metallurgy, petrochemical equipment, mining equipment, textile equipment, water conservancy machinery, agriculture, forestry, animal husbandry and fishing, environmental protection machinery and other manufacturing industries.

6 Mainly includes: railway, automobile, ship, aircraft transportation equipment manufacturing.

7 Mainly includes: motors, generators, transmission and distribution and control equipment, wire and cable, battery manufacturing.

8 Mainly includes: communications equipment, radar, integrated circuit manufacturing, electronic computers, semiconductor devices.

9 Mainly includes: optical instruments, meteorological instruments, industrial automation and electrical instruments, measuring instruments, copiers and offset presses.

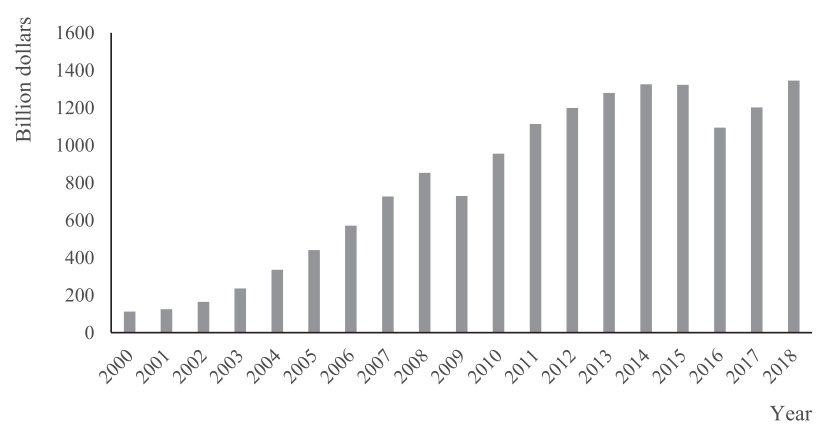

Fig. 1. Changes in China's equipment manufacturing export from 2000 to 2018. Note: The data comes from the UN Comtrade, and is expressed in billion US dollars.

2001. Affected by the financial crisis, the export value of China's equipment manufacturing industry declined in 2009. In 2010, the economy gradually recovered, and China adopted measures to resume foreign trade development, which led to an increase of $30.87 \%$ in exports of China's equipment manufacturing industry compared with 2009. In 2011, the export value of China's equipment manufacturing industry exceeded the US\$1 trillion. From 2011 to 2014, the export value of China's equipment manufacturing industry has been showing an upward trend. However, effected by the new economic normal in 2015, shrinking external demand has caused a decline in China's equipment manufacturing exports, it was not until 2017 that it began to gradually recover (Fig. 1).

\section{Export Scale of Sub-Industries of China's Equipment Manufacturing Industry}

From the perspective of sub-industries, the exports of the seven major industries of China's equipment manufacturing industry showed a trend of increasing volatility before 2015, but the changes in exports after 2016 have a large gap (Fig. 2). The export of the electrical machinery and equipment manufacturing industry and the instrumentation, cultural and office machinery manufacturing industry fell sharply in 2016 , but the export of the electronic communication equipment manufacturing industry has increased rapidly, and other industries are in a steady increasing trend. This is because China's industrial structure is actively adjusting.

\section{Measurement of China's Equipment Manufacturing Export Carbon Emissions}

\section{Construction of Export Carbon Emission Measurement Model}

The input-output method is currently the mainstream method for measuring carbon emissions. The basic form of the input-output model is: 


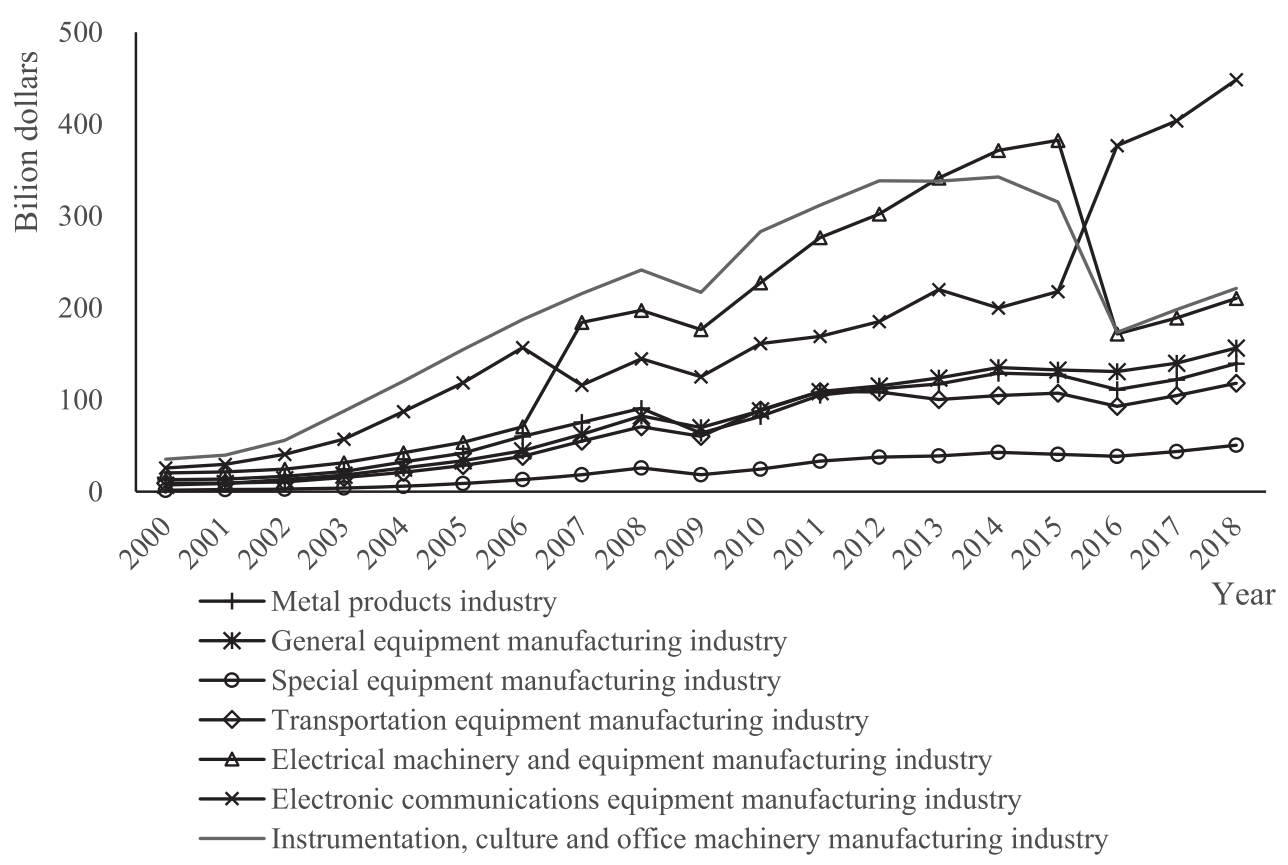

Fig. 2. Export of China's equipment manufacturing industry by sub-industry from 2000 to 2018 . Note: The data comes from the UN Comtrade, and is expressed in billion US dollars.

$$
X=A X+Y
$$

The model after the transformation is:

$$
X=(I-A)^{-1} Y
$$

...where $A$ is the direct consumption coefficient matrix, $I$ is the unit matrix, $X$ is the total social output matrix, and $Y$ is the social final consumer product matrix.

To apply the input-output method into the calculation of carbon emissions, two important concepts need to be introduced: the direct carbon emission coefficient and the complete carbon emission coefficient. And multiply the value of the complete carbon emission coefficient by the export value to obtain the carbon emission value.

The calculation of export carbon emissions is mainly divided into three steps. The first step is to calculate the direct carbon emission factor:

$$
T C E_{j}=\frac{C E_{j}}{X_{j}}
$$

...where $T C E_{j}$ is the direct carbon emission coefficient of $j$ sector, $C E_{j}$ is the total direct carbon emission of $j$ sector, and $X_{j}$ is the total output of $j$ sector.

The second step is to calculate the complete carbon emission coefficient:

$$
D C E_{j}=T C E_{j}(I-A)^{-1}
$$

...where $D C E_{j}$ is the complete carbon emission coefficient, $T C E_{j}$ is the direct carbon emission coefficient, $A$ is the direct consumption coefficient matrix, and $I$ is the unit matrix.

The third step is to calculate carbon emissions:

$$
C_{j}=D C E_{j} \times Y_{j}=T C E_{j}(I-A)^{-1} Y_{j}
$$

...where $C_{j}$ is the carbon emissions of $j$ sector, $Y_{j}$ is the export value of $j$ sector.

\section{Calculation Results of Export Carbon Emissions of China's Equipment Manufacturing Industry}

At first, we calculate the direct carbon emission coefficients of each sub-sector of China's equipment manufacturing industry from 2000-2018. Then, the full carbon emission coefficients of each sub-sector of China's equipment manufacturing industry are calculate. Finally, we can get the carbon emissions of various sectors of China's equipment manufacturing industry (Table 1).

From 2000 to 2007, the carbon emissions of China's equipment manufacturing industry's exports increased rapidly to 144.98 million tons. With the progress of China's green development, carbon emissions gradually reduced to 47.20 million tons in 2016. But in 2017, the carbon emissions started to rise again with the increasing of export. From the perspective of subindustries, the industry with the most carbon emissions is the general equipment manufacturing industry, and the industry with the least carbon emissions is the special equipment manufacturing industry. 
Table. 1. Export carbon emissions of equipment manufacturing industry and sub-industries from 2000 to 2018 (unit: ten thousand tons).

\begin{tabular}{|c|c|c|c|c|c|c|c|c|}
\hline & $\begin{array}{l}\text { Metal } \\
\text { products } \\
\text { industry }\end{array}$ & $\begin{array}{l}\text { General } \\
\text { equipment } \\
\text { industry }\end{array}$ & $\begin{array}{l}\text { Special } \\
\text { equipment } \\
\text { industry }\end{array}$ & $\begin{array}{l}\text { Transporta- } \\
\text { tion equipment } \\
\text { industry }\end{array}$ & $\begin{array}{l}\text { Electrical } \\
\text { machinery } \\
\text { and } \\
\text { equipment } \\
\text { industry }\end{array}$ & $\begin{array}{c}\text { Electronic } \\
\text { communication } \\
\text { equipment } \\
\text { industry }\end{array}$ & $\begin{array}{l}\text { Instrumenta- } \\
\text { tion, culture and } \\
\text { office machinery } \\
\text { manufacturing } \\
\text { industry }\end{array}$ & $\begin{array}{l}\text { Equipment } \\
\text { industry }\end{array}$ \\
\hline 2000 & 1664.0 & 1659.3 & 339.1 & 1394.0 & 1148.0 & 613.5 & 2168.9 & 8986.8 \\
\hline 2001 & 1710.1 & 1842.7 & 485.9 & 1237.2 & 1054.8 & 648.6 & 2260.5 & 9239.9 \\
\hline 2002 & 1647.2 & 1912.0 & 390.7 & 942.9 & 915.7 & 715.3 & 2380.1 & 8903.8 \\
\hline 2003 & 1655.1 & 2034.7 & 473.7 & 962.5 & 959.1 & 725.1 & 3458.8 & 10269.0 \\
\hline 2004 & 1821.6 & 2182.7 & 616.1 & 1281.0 & 937.7 & 946.3 & 2071.4 & 9856.7 \\
\hline 2005 & 2245.2 & 853.2 & 856.7 & 1712.9 & 1056.1 & 1214.3 & 2229.2 & 10167.5 \\
\hline 2006 & 2509.7 & 3556.4 & 995.7 & 1847.8 & 1073.0 & 1329.8 & 2191.9 & 13504.3 \\
\hline 2007 & 2543.7 & 3873.0 & 1052.2 & 1998.0 & 2103.0 & 833.7 & 2094.9 & 14498.4 \\
\hline 2008 & 2319.8 & 3322.0 & 1030.2 & 2103.1 & 1886.1 & 1042.3 & 2275.1 & 13978.6 \\
\hline 2009 & 1518.9 & 3027.5 & 659.4 & 1436.1 & 2222.9 & 815.8 & 2158.2 & 11838.7 \\
\hline 2010 & 1417.6 & 2982.5 & 767.5 & 1631.5 & 1882.0 & 841.2 & 2283.6 & 11805.9 \\
\hline 2011 & 1289.9 & 3823.7 & 694.7 & 1693.2 & 2452.7 & 532.5 & 1441.0 & 11927.9 \\
\hline 2012 & 772.2 & 2012.9 & 309.0 & 945.5 & 1321.1 & 357.2 & 1081.7 & 6799.6 \\
\hline 2013 & 1062.7 & 1739.5 & 291.3 & 782.4 & 1706.0 & 299.7 & 1137.3 & 7019.0 \\
\hline 2014 & 887.7 & 1668.3 & 292.4 & 634.8 & 1544.3 & 247.3 & 848.7 & 6123.5 \\
\hline 2015 & 865.6 & 1742.4 & 254.2 & 603.3 & 1778.1 & 279.4 & 700.1 & 6223.1 \\
\hline 2016 & 751.3 & 1755.5 & 216.5 & 450.4 & 668.7 & 523.2 & 354.8 & 4720.4 \\
\hline 2017 & 1049.8 & 1546.8 & 277.5 & 747.6 & 395.0 & 664.8 & 353.0 & 5034.5 \\
\hline 2018 & 2334.1 & 1223.6 & 201.6 & 1110.1 & 321.6 & 1015.7 & 226.7 & 6433.3 \\
\hline
\end{tabular}

Note: The data comes from China Statistical Yearbook and Input-output table compiled by the National Bureau of Statistics.

\section{Measurement of the Decoupling Effect of Export Carbon Emissions of China's Equipment Manufacturing}

\section{Decoupling Elasticity Index Model}

This paper selects two sets of time-series data of equipment manufacturing export trade value and carbon emissions generated from 2000 to 2018, taking two years as a stage, using a decoupling model to analyze the status of the two in 19 years, and constructing Tapio decoupling model as follows:

$$
t=\frac{\Delta C \mathrm{O}_{2} / \mathrm{CO}_{2}}{\Delta E T / E T}
$$

...where $t$ is the decoupling elasticity index of $\mathrm{CO}_{2}$ emissions and exports; $\mathrm{CO}_{2}$ is carbon emissions; $\mathrm{\triangle CO}_{2}$ is the ratio of the current period to the base period, showing the change in carbon emissions; $E T$ is the current export value; $\triangle E T$ is the ratio of the current period to the base period, showing the value of changes in exports.

According to the decoupling elasticity index, it can be divided into 8 types of decoupling: strong decoupling, weak decoupling, degeneration decoupling, expansion coupling, degeneration coupling, expansion negative decoupling, weak negative decoupling, strong negative decoupling. Strong decoupling reflects the reduction of carbon emissions, while the increase in exports is in line with the development requirements of a low-carbon economy. It is the most ideal decoupling state; weak decoupling reflects the simultaneous increase in carbon emissions and exports, but the increase in carbon emissions is significantly lower than the increase in exports. The quantity is the second best state after strong decoupling (Fig. 3).

Let point $\mathrm{O}$ be the initial state. Compared with point $\mathrm{O}$, any point in the fourth quadrant has an increase in export volume and a reduction in carbon emissions, which is a Pareto improvement. Therefore, the area of the fourth quadrant (ie, the strong decoupling area) is the Pareto improvement area. In order to further 


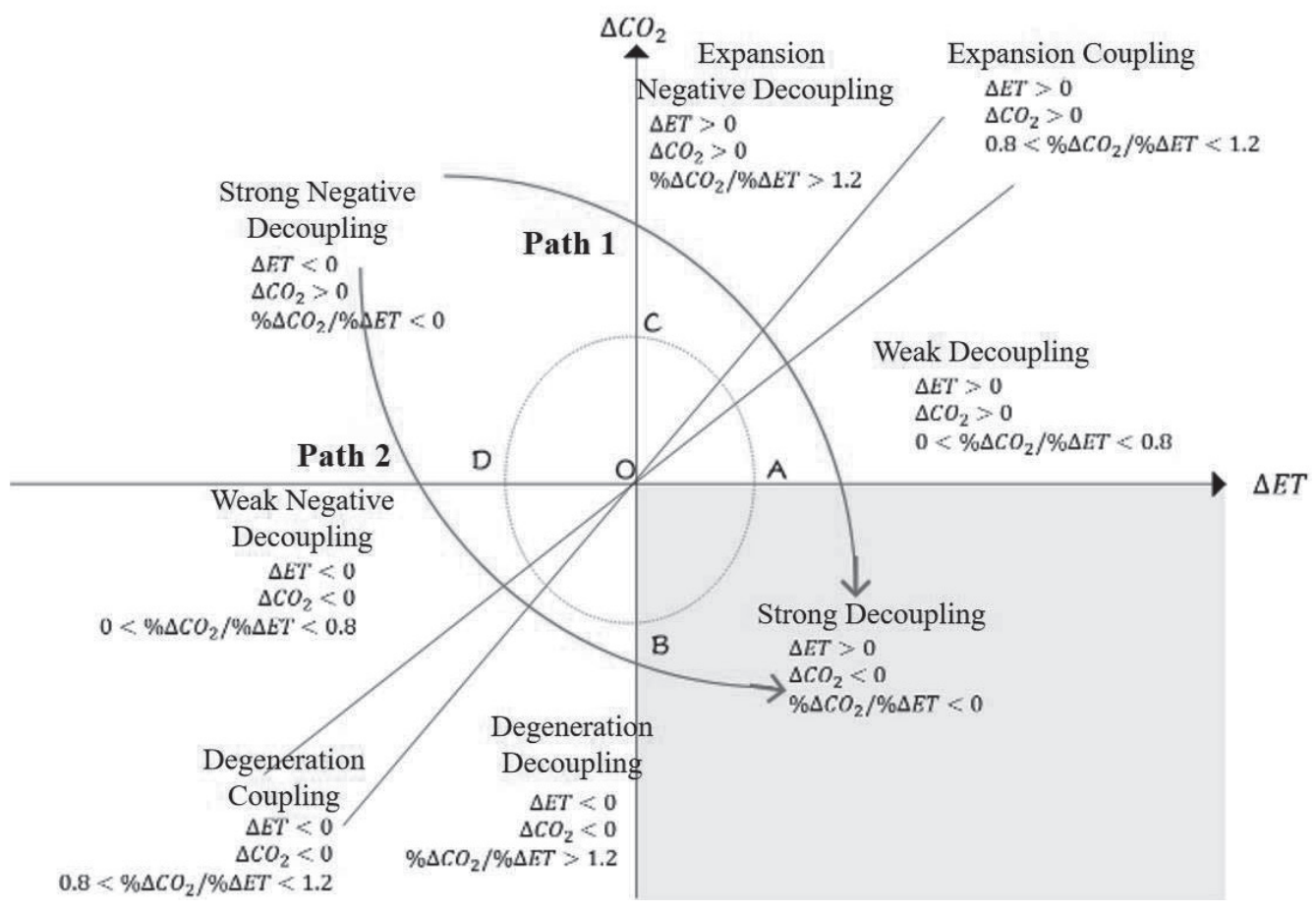

Fig. 3. Decoupling elastic state and characteristics. Note: The material is organized according to Tapio decoupling model.

compare the advantages and disadvantages of other decoupling types, it is necessary to analyze the points $\mathrm{A}, \mathrm{B}, \mathrm{C}$, and $\mathrm{D}$ on the coordinate axis. From point $\mathrm{O}$ to point $\mathrm{A}$ and from point $\mathrm{O}$ to point $\mathrm{B}$, satisfying the conditions of no reduction in exports and no increase in carbon emissions are also Pareto improvements. Point $\mathrm{A}$ is near the weak decoupling area, and point $\mathrm{B}$ is near the degenerate decoupling area, so $\mathrm{A}$ is better than $\mathrm{B}$; similarly, point $\mathrm{C}$ is better than $\mathrm{D}$. Therefore, the order of decoupling effect is: $\mathrm{A}>\mathrm{B}>\mathrm{C}>\mathrm{D}$. According to this judgment, the expansion coupling is better than the degeneration coupling, and the expansion negative decoupling is better than the weak negative decoupling. Furthermore, the order of the eight decoupling modes is as follows: strong decoupling, weak decoupling, degeneration decoupling, expansion coupling, degeneration coupling, expansion negative decoupling, weak negative decoupling, and strong negative decoupling.

Strong decoupling is the ultimate goal of the decoupling effect, and there are two ways to achieve this goal. The first path starts from strong negative decoupling, through expansion negative decoupling, expansive coupling, and weak decoupling, and finally reaches strong decoupling. This path mainly achieves decoupling after passing through the first quadrant, that is, in the path optimization, the growth rate of exports needs to be faster than the growth rate of carbon emissions. It is called the path of increasing economic growth. The second path starts from strong negative decoupling, after weak negative decoupling, degeneration coupling, and degeneration decoupling, and finally reaches strong decoupling. This path mainly achieves decoupling after passing through the third quadrant. That is, in the path optimization, it is necessary to make the carbon emission decline rate faster than the export decline rate, which is called the path of decreasing energy consumption.

\section{Decoupling Level Index Setting}

Since the decoupling elasticity index reflects the static decoupling status in different years, it cannot reflect the overall decoupling situation. Therefore, in order to reflect the overall decoupling situation of China's equipment manufacturing industry in 19 years, the concept of decoupling grade index is introduced.

According to the completion of decoupling, set the initial state is 0 , and the decoupling level is from 1 to 8 . The higher the level is, the better the decoupling effect is. Where the 1-4 state is uncompleted decoupling, and the 5-6 state has the characteristics of decoupling to some extent, but it is unstable; 7-8 status is complete decoupling. The decoupling level index (indicated by $\mathrm{T}$ ) is seen as the average number of decoupling levels in different years. The larger the coefficient, the more significant the decoupling effect. When $1 \leq \mathrm{T} \leq 4.5$, it is uncompleted decoupling; when $4.5<\mathrm{T} \leq 6.5$, it is unstable Decoupling; when $6.5<\mathrm{T} \leq 8$, it is complete decoupling (Table 2).

\section{Data Sources}

Based on the authentic authority and availability of the data sources, the data sources in this paper mainly include the input-output table compiled by the National 
Table. 2. Decoupling elastic state and characteristics.

\begin{tabular}{|c|c|c|c|}
\hline Decoupling status & $\begin{array}{c}\text { Decoupling } \\
\text { level }\end{array}$ & Characteristics of decoupling status & The value of decoupling level index \\
\hline Strong negative decoupling & 1 & \multirow{4}{*}{ Uncompleted decoupling } & \multirow{4}{*}{$1 \leq \mathrm{T} \leq 4.5$} \\
\hline Weak negative decoupling & 2 & & \\
\hline Expansion negative decoupling & 3 & & \\
\hline Degeneration coupling & 4 & & \\
\hline Expansion coupling & 5 & \multirow{2}{*}{ Unstable decoupling } & \multirow{2}{*}{$4.5<\mathrm{T} \leq 6.5$} \\
\hline Degeneration decoupling & 6 & & \\
\hline Weak decoupling & 7 & \multirow{2}{*}{ Complete decoupling } & \multirow{2}{*}{$6.5<\mathrm{T} \leq 8$} \\
\hline Strong decoupling & 8 & & \\
\hline
\end{tabular}

Note: The material is organized according to Tapio decoupling model.

Bureau of Statistics, the China Statistical Yearbook, the China Energy Statistical Yearbook compiled by the National Bureau of Statistics, and the United Nations Commodity Trade Database. For the export value of China's equipment manufacturing industry, this paper integrates data from China Statistical Yearbook and the United Nations Commodity Trade Database. The data of energy consumption comes from China Statistical Yearbook. For the sector classification of export trade, the Harmonized Commodity Name and Coding System of World Customs Organization is used (Table 3).

\section{Results and Discussion}

Analysis of the Overall Decoupling Effect of China's Equipment Manufacturing Industry

The decoupling situation of China's equipment manufacturing industry is as follows: (1) From 2000 to 2005 , there was an alternate state of strong and weak decoupling. In 2001, after China's accession to the World Trade Organization, it led to a substantial increase in foreign trade exports. However, because

Table. 3. Integration of equipment manufacturing industry.

\begin{tabular}{|c|c|c|c|}
\hline Sector integration & Input-output table & $\begin{array}{l}\text { Energy consumption divided by } \\
\text { industry }\end{array}$ & HS code \\
\hline $\begin{array}{l}\text { S1 Metal Products Manufacturing } \\
\text { Industry }\end{array}$ & $\begin{array}{l}\text { Metal Products Manufacturing } \\
\text { Industry }\end{array}$ & $\begin{array}{l}\text { Metal Products Manufacturing } \\
\text { Industry }\end{array}$ & Chapters 73-83 \\
\hline $\begin{array}{l}\text { S2 General Equipment } \\
\text { Manufacturing Industry }\end{array}$ & $\begin{array}{l}\text { General Equipment Manufacturing } \\
\text { Industry }\end{array}$ & $\begin{array}{l}\text { General Equipment Manufacturing } \\
\text { Industry }\end{array}$ & $\begin{array}{l}\text { Chapter 84: 1-26, } \\
54-68,74-75,80-87\end{array}$ \\
\hline $\begin{array}{l}\text { S3 Special Equipment } \\
\text { Manufacturing Industry }\end{array}$ & $\begin{array}{l}\text { Special Equipment Manufacturing } \\
\text { Industry }\end{array}$ & $\begin{array}{l}\text { Special Equipment Manufacturing } \\
\text { Industry }\end{array}$ & $\begin{array}{c}\text { Chapter 84: 27-39, } \\
44-53,76-79\end{array}$ \\
\hline \multirow{2}{*}{$\begin{array}{l}\text { S4 Transportation Equipment } \\
\text { Manufacturing Industry }\end{array}$} & \multirow{2}{*}{$\begin{array}{l}\text { Transportation Equipment } \\
\text { Manufacturing Industry }\end{array}$} & $\begin{array}{c}\text { Automotive Manufacturing } \\
\text { Industry }\end{array}$ & \multirow[b]{2}{*}{ Chapter 86-89 } \\
\hline & & $\begin{array}{l}\text { Railway, Shipbuilding, Aerospace } \\
\text { and other Transportation } \\
\text { Equipment Manufacturing Industry }\end{array}$ & \\
\hline $\begin{array}{c}\text { S5 Electrical Machinery and } \\
\text { Equipment Manufacturing } \\
\text { Industry }\end{array}$ & $\begin{array}{l}\text { Electrical Machinery and Equip- } \\
\text { ment Manufacturing Industry }\end{array}$ & $\begin{array}{l}\text { Electrical Machinery and } \\
\text { Equipment Manufacturing } \\
\text { Industry }\end{array}$ & $\begin{array}{c}\text { Chapter } 85: 1-16,30 \\
32-39,43-48\end{array}$ \\
\hline $\begin{array}{c}\text { S6 Electronic } \\
\text { Communication Equipment } \\
\text { Manufacturing Industry }\end{array}$ & $\begin{array}{l}\text { Communication Equipment, } \\
\text { Computer and Other Electronic } \\
\text { Equipment Manufacturing } \\
\text { Industry }\end{array}$ & $\begin{array}{l}\text { Computer, Communication and } \\
\text { Other Electronic Equipment } \\
\text { Manufacturing Industry }\end{array}$ & $\begin{array}{c}\text { Chapter } 85: 17-29,31 \text {, } \\
40-42\end{array}$ \\
\hline \multirow{2}{*}{$\begin{array}{l}\text { S7 Instrumentation and Culture, } \\
\text { Office Machinery Manufacturing } \\
\text { Industry }\end{array}$} & $\begin{array}{l}\text { Instrumentation Manufacturing } \\
\text { Industry }\end{array}$ & \multirow{2}{*}{$\begin{array}{l}\text { Instrumentation, Culture and Office } \\
\text { Machinery Manufacturing Industry }\end{array}$} & \multirow{2}{*}{$\begin{array}{c}\text { Chapter 84: 40-43, } \\
69-73,90-92,95\end{array}$} \\
\hline & $\begin{array}{l}\text { Paper-making, Printing, Cultural, } \\
\text { Educational and Sporting Goods }\end{array}$ & & \\
\hline
\end{tabular}

Note: The data comes from the Input-output table compiled by the National Bureau of Statistics, China Energy Statistical Yearbook and the World Customs Organization. 
Table. 4. Decoupling elasticity and decoupling status of China's equipment manufacturing export and carbon emissions from 2000 to 2018.

\begin{tabular}{|c|c|c|c|c|}
\hline Years & $\mathrm{ACO} / \mathrm{CO}_{2}$ & $\triangle E X P / E X P$ & Decoupling elasticity index & Decoupling status \\
\hline $2000-2001$ & 0.0274 & 0.1048 & 0.2614 & Weak decoupling \\
\hline 2001-2002 & -0.0377 & 0.2346 & -0.1609 & Strong decoupling \\
\hline $2002-2003$ & 0.1329 & 0.3043 & 0.4369 & Weak decoupling \\
\hline $2003-2004$ & -0.0418 & 0.2960 & -0.1413 & Strong decoupling \\
\hline 2004-2005 & 0.0306 & 0.2301 & 0.1328 & Weak decoupling \\
\hline 2005-2006 & 0.2471 & 0.2081 & 1.1871 & Expansion coupling \\
\hline 2006-2007 & 0.0686 & 0.1771 & 0.3873 & Weak decoupling \\
\hline $2007-2008$ & -0.0372 & 0.0658 & -0.5649 & Strong decoupling \\
\hline 2008-2009 & -0.1807 & -0.1873 & 0.9648 & Degeneration coupling \\
\hline 2009-2010 & -0.0028 & 0.2290 & -0.0121 & Strong decoupling \\
\hline 2010-2011 & 0.0102 & 0.1012 & 0.1010 & Weak decoupling \\
\hline 2011-2012 & -0.7542 & 0.0490 & -15.3822 & Strong decoupling \\
\hline $2012-2013$ & 0.0313 & 0.0453 & 0.6905 & Weak decoupling \\
\hline 2013-2014 & -0.1462 & 0.0263 & -5.5610 & Strong decoupling \\
\hline 2014-2015 & 0.0160 & 0.0124 & 1.2896 & Expansion negative decoupling \\
\hline 2015-2016 & -0.3183 & -0.1335 & 2.3838 & Degeneration decoupling \\
\hline 2016-2017 & 0.0624 & 0.1039 & 0.6001 & Weak decoupling \\
\hline $2017-2018$ & 0.2174 & 0.0881 & 2.4689 & Expansion negative decoupling \\
\hline
\end{tabular}

Note: The data comes from China Statistical Yearbook and input-output table compiled by the National Bureau of Statistics.

production activities were mainly labor-intensive, the growth rate of carbon emissions was slow. In 2002, the export trade of China's equipment manufacturing industry developed steadily, and the demand for the heavy manufacturing industry increased, which caused an increase in environmental pollution [7]. In 2003, China paid more attention to energy conservation and emission reduction, and issued the Notice on the Activities Arrangements for the 2003 National Energy Conservation Publicity Week. Large-scale publicity activities have been carried out across the country to make the relationship between export trade and carbon emissions become Strong decoupling state. And since 2004, the Outline of Energy Medium and Long-term Development Plan (2004-2020) was formulated, which is a milestone event in China's environmental protection field, and clearly put forward the goal of building an energy-saving society. (2) From 2005 to 2006, it showed a state of expansion coupling. At this stage, China's participation in the international division of labor has deepened, the increase in export trade has increased, and the production of high-energy-consuming and highcarbon-emission products has also increased. (3) From 2006 to 2008, it once again showed an alternate state of strong and weak decoupling. In 2006, the State Council issued a decision to strengthen energy conservation work and formulated requirements for reducing energy consumption in heavy industries such as manufacturing. In the same year, the Several Opinions on Accelerating the Revitalization of the Equipment Manufacturing Industry was issued, fully demonstrating the importance attached to the development of the equipment manufacturing industry. The implementation of this series of measures and laws and regulations has made the carbon emissions of the equipment manufacturing industry a relatively optimistic state [29]. (4) From 2008 to 2009 , it showed a state of declining coupling. This stage is mainly affected by the global financial crisis, and China's weak exports have reduced the export trade volume of the equipment manufacturing industry, leading to a reduction in carbon emissions. (5) From 2009 to 2014, strong and weak decoupling fluctuations existed. At this stage, the domestic and international economy gradually recovered, and the export trade situation improved, which led to an increase in the export of equipment manufacturing. At the same time, the improvement of the domestic economic environment caused the demand for energy to gradually increase. In 2011, the pilot carbon emissions trading rights were steadily implemented, and the carbon emissions trading rights market was launched in 2013. These policies and measures have reduced carbon emissions [30]. 


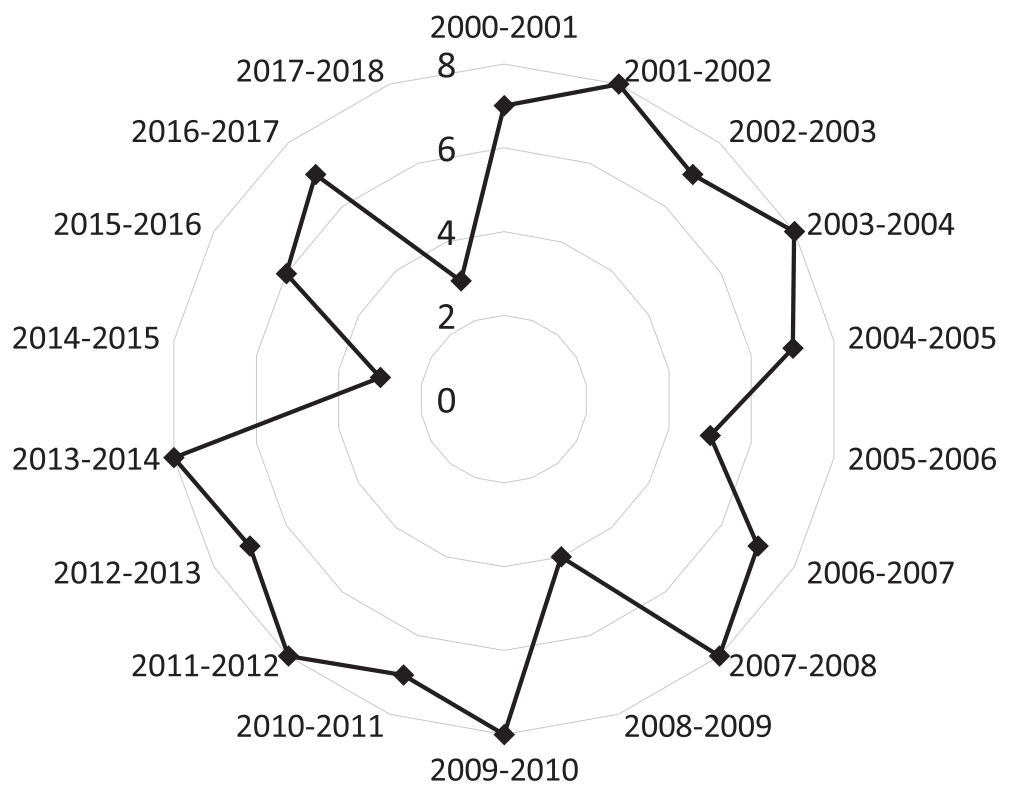

Fig. 4. Radar chart of the decoupling effect of China's equipment manufacturing industry from 2000 to 2018.

(6) From 2014 to 2015, there was an expansive negative decoupling. This shows that the world economy has basically recovered, and carbon emissions have increased with the growth of export trade. (7) Decline decoupling and weak decoupling occurred successively from 2015 to 2017. The reasons are that on the one hand, the export trade under the new normal of the economy is weak, and on the other hand, the Energy Conservation and Emission Reduction formulated, resulting in a reduction in carbon emissions. (8)
In 2017-2018, expansionary negative decoupling reappeared. The green development of China's equipment manufacturing industry has encountered a bottleneck, and the growth rate of carbon emissions is much higher than the growth rate of export trade (Table 4).

To sum up, during the 19 years, 6 years showed a strong decoupling state, and 7 years showed a weak decoupling state. According to the decoupling level index setting, we perform a radar chart of the decoupling

Table. 5. The number of occurrences of coupling status of sub-industries from 2000 to 2018.

\begin{tabular}{|c|c|c|c|c|c|c|c|c|}
\hline $\begin{array}{c}\text { Equipment Manu- } \\
\text { facturing } \\
\text { Industry }\end{array}$ & $\begin{array}{c}\text { Strong } \\
\text { decoupling }\end{array}$ & $\begin{array}{c}\text { Weak } \\
\text { decoupling }\end{array}$ & $\begin{array}{c}\text { Degeneration } \\
\text { decoupling }\end{array}$ & $\begin{array}{c}\text { Expansion } \\
\text { coupling }\end{array}$ & $\begin{array}{c}\text { Degeneration } \\
\text { coupling }\end{array}$ & $\begin{array}{c}\text { Expansion } \\
\text { negative } \\
\text { decoupling }\end{array}$ & $\begin{array}{c}\text { Weak } \\
\text { negative } \\
\text { decoupling }\end{array}$ & $\begin{array}{c}\text { Strong } \\
\text { negative } \\
\text { decoupling }\end{array}$ \\
\hline $\begin{array}{c}\text { Metal products } \\
\text { industry }\end{array}$ & 7 & 5 & 1 & 1 & 1 & 3 & 0 & 0 \\
\hline $\begin{array}{c}\text { General equipment } \\
\text { industry }\end{array}$ & 8 & 6 & 0 & 0 & 0 & 2 & 1 & 1 \\
\hline $\begin{array}{c}\text { Special equipment } \\
\text { industry }\end{array}$ & 7 & 6 & 2 & 3 & 0 & 0 & 0 & 0 \\
\hline $\begin{array}{c}\text { Transportation } \\
\text { equipment industry }\end{array}$ & 4 & 6 & 4 & 2 & 0 & 2 & 0 & 0 \\
\hline $\begin{array}{c}\text { Electrical machin- } \\
\text { ery and equipment } \\
\text { industry }\end{array}$ & 8 & 3 & 2 & 1 & 0 & 3 & 0 & 0 \\
\hline $\begin{array}{c}\text { Electronic commu- } \\
\text { nication equipment } \\
\text { industry }\end{array}$ & 3 & 6 & 3 & 3 & 0 & 3 & 1 \\
\hline $\begin{array}{c}\text { Instrumenta- } \\
\text { tion, culture and } \\
\text { office machinery } \\
\text { manufacturing } \\
\text { industry }\end{array}$ & 8 & 4 & 2 & 1 & 0 & & 0 \\
\hline
\end{tabular}


Table. 6. Decoupling level Index and Decoupling Status of China's Equipment Manufacturing sub-industries from 2000 to 2018.

\begin{tabular}{|c|c|c|}
\hline Equipment Manufacturing Industry & Decoupling level Index & Decoupling Status \\
\hline Metal Products Manufacturing Industry & 6.333 & Unstable decoupling \\
\hline General Equipment Manufacturing Industry & 6.389 & Unstable decoupling \\
\hline Special Equipment Manufacturing Industry & 6.944 & Completed decoupling \\
\hline Transportation Equipment Manufacturing Industry & 6.333 & Unstable decoupling \\
\hline Electrical Machinery and Equipment Manufacturing Industry & 6.222 & Unstable decoupling \\
\hline Electronic Communication Equipment Manufacturing Industry & 6.000 & Unstable decoupling \\
\hline Instrumentation and Culture, Office Machinery Manufacturing Industry & 6.389 & Unstable decoupling \\
\hline
\end{tabular}

effect of the equipment manufacturing industry from 2000 to 2018 (Fig. 4), which is divided into 8 levels in turn, and the level closer to the periphery reflects the decoupling effect is more obvious. The decoupling rating index of the equipment manufacturing industry is 6.556, which is in a completed decoupling state. However, its rank index is lower, and it is generally close to the weak decoupling level [27].

\section{Analysis of the Decoupling Effect of Sub-Industries of China's Equipment Manufacturing Industry}

The decoupling effect was calculated for 7 subsectors (Table 5), and most of the sub-sectors showed strong decoupling or weak decoupling in most years. Where the general equipment manufacturing industry and the special equipment manufacturing industry performed well, with 14 and 13 years respectively belonging to the state of strong decoupling and weak decoupling.

It can be seen from the decoupling grade index (Table 6) that the general equipment manufacturing industry and the special equipment manufacturing industry index are higher, and the decoupling effect is significant. The decoupling index of other industries is lower than 6.5, which is in an unstable decoupling state. Judging from the six unstable decoupling industries, many of these industries are in the state of weak decoupling, expansion coupling and expansion negative decoupling, which is located in the first quadrant of the decoupling elastic state diagram, where carbon emissions will increase with the increase in exports [24]. Therefore, combined with the analysis of Fig. 3, it can be seen that the optimization path of China's equipment manufacturing industry mainly focuses on stabilizing foreign trade growth.

\section{Conclusion}

Through the above research, we can see that the decoupling of China's equipment manufacturing carbon emissions and export growth has achieved initial results. The main conclusions include:
(1) From the overall perspective of the equipment manufacturing industry, from 2000 to 2018, six years were in an optimistic strong decoupling state, and seven years were in a relatively optimistic weak decoupling state. The analysis of the decoupling level index shows that in the past 19 years, China's equipment manufacturing export trade and carbon emissions have completed decoupling, reaching a level of weak decoupling. It shows that the government policy has achieved certain results and can maintain a reduction in carbon emissions for a period of time. There are also five years that show decoupling, expansion coupling, degeneration decoupling, or expansion negative decoupling. Therefore, the problem of carbon emission reduction has not been fundamentally resolved, and the relevance of carbon emission reduction measures needs to be further strengthened.

(2) In terms of sub-industries, the decoupling status of the special equipment manufacturing industry is significant. The decoupling level index shows that only this industry is in a decoupling state; while the other sub-sectors are in an unstable decoupling state. The decoupling effect of the electronic communication equipment manufacturing industry is the weakest. Therefore, different emission reduction policies need to be implemented for different sub-sectors.

In order to enhance the decoupling effect between the export carbon emissions and export trade of China's equipment manufacturing, different paths should be adopted according to China's foreign trade development situation:

(1) The first path is increasing economic growth. This path is adopted when dealing with the downward pressure on foreign trade to stabilize the growth of export trade. It is a path that should be emphasized at present. The policy focuses on: Firstly, optimize the export structure, gradually reduce the proportion of labor- and resource-intensive low-value-added equipment manufacturing in overall trade, and increase the proportion of high-value-added equipment manufacturing such as technology-intensive and service trade. The second is to promote the service industry of equipment manufacturing, strengthen the in-depth integration of equipment manufacturing and service 
industries, increase the input of service elements in the production of equipment manufacturing, expand upstream in global value chains such as R\&D and design, and increase the added value of export products. Improve the level of industrial division and collaboration in the equipment manufacturing and service industries to reduce corporate financing costs and broaden external marketing channels. The third is to establish an investment mechanism for export enterprises in low-carbon technological innovation and improve the scientific research and talent management system. Improve the efficiency of R\&D resource allocation and output level, and accelerate the cultivation of lowcarbon leading products and core technologies with independent intellectual property rights.

(2) The second path is decreasing energy consumption. This approach is adopted when dealing with the pressure of carbon emission reduction and when the foreign trade situation is getting better. The policy focuses on: First, improve the energy consumption structure of foreign trade enterprises, gradually reduce the excessive dependence of traditional equipment manufacturing on coal and other fuels, adjust the energy consumption structure, continuously improve the emission reduction effect of renewable energy, and promote the traditional focus on fossil fuels energy consumption to shift to a diversified, efficient, green and environmentally friendly modern energy consumption. The second is to vigorously promote the technological progress, development and application of renewable energy such as solar energy, wind power and hydro power. The third is to close down highenergy-consuming enterprises, restrict the export of high-energy-consumption equipment manufacturing products, and encourage and guide enterprises to export green and environmental-friendly products. The fourth is to establish and improve China's carbon emissions trading market, clarify trading subjects, trading products and pricing mechanisms, and rationally allocate carbon emission quotas. Strengthen the carbon trading market supervision system to ensure that carbon transfer is open, fair and transparent. Explore the establishment of a carbon financial market to prevent the loss of carbon resources and strive for currency dominance.

\section{Acknowledgment}

This paper is supported by the National Social Science Fund Project: the Belt and Road Research on the Cooperation and Sharing Mechanism of the Value Chain of Equipment Manufacturing of Countries along the Belt and Road (Grant No. 17BJY071).

\section{Conflicts of Interest}

The authors declare no conflict of interest.

\section{References}

1. EDGAR G.H, Carbon fueling complex global value chains tripled in the period 1995-2012. Energy Economics, 86, 2020.

2. HAO Y., HUANG Y. Exploring the Nexus of Energy Consumption Structure and $\mathrm{CO}_{2}$ Emissions in China: Empirical Evidence Based on the Translog Production Function. Polish Journal of Environmental Studies, 27, 2541, 2018.

3. CHUANWANG S., ZHI L., TIEMENG M., RUNYONG $\mathrm{H}$. Carbon efficiency and international specialization position: Evidence from global value chain position index of manufacture. Energy Policy, 128, 235, 2019.

4. MICHIEKA N.M., FLETCHER J.J., BURNETT J.W. An empirical analysis of the role of China's exports on $\mathrm{CO}_{2}$ emissions. Applied energy, 104, 258, 2013.

5. WEBER C.L., MATTHEWS H.S. Embodied environmental emissions in u.S. International trade, 19972004. Environmental Science \& Technology, 41(14), 4875, 2007.

6. QI J., GUAN J. Research on the relationship between China's export trade, carbon emissions and economic growth. Henan Science, 33 (11), 2016, 2015 [In Chinese].

7. DU Y., ZHANG W. Research on the growth of China's export trade embodied carbon emissions and its driving factors. International Trade Issues, 3, 97, 2012 [In Chinese].

8. ZHANG F., JIANG T. Research on the Relationship between Carbon Emissions and Export Trade and Economic Growth - A Quantitative Analysis of Shandong Province's Data from 1984 to 2008. Ecological Economy, 2, 61-64+101, 2011 [In Chinese].

9. ZHANG M., MU H., NING Y., SONG Y. Decomposition of energy-related $\mathrm{CO}_{2}$ emission over 1991-2006 in china. Ecological Economics, 68, 2122, 2009.

10. SUN X., ZANG X. An empirical analysis of the energy consumption and environmental effects of China's export trade - Based on the mixed unit input-output model. Quantitative Economic Technical Economic Research, 26 (4), 33, 2009 [In Chinese].

11. DENG B., SONG D. Research on the relationship between China's foreign trade, FDI and environmental pollution: 1995-2005. International Trade Issues, 4, 101, 2008 [In Chinese].

12. SHUI B., HARRISS R.C. The role of $\mathrm{CO}_{2}$ embodiment in us-china trade. Energy Policy, 34, 4063, 2006.

13. AHMAD N., WYCKOFF A. Carbon dioxide emissions embodied in international trade of goods. 2003.

14. KENNETH R. Indicators to Measure Decoupling of Environmental Pressure from Economic Growth. Paris, 2002.

15. VEHMAS J., KAIVO-OJA J., LUUKKANEN J. Global trends of linking environmental stress and economic growth: Total primary energy supply and $\mathrm{CO}_{2}$ emissions in the european union, japan, USA, china, india and brazil. 2019.

16. TAPIO P. Towards a theory of decoupling: Degrees of decoupling in the eu and the case of road traffic in finland between 1970 and 2001. Transport Policy, 12 (2), 137, 2005.

17. LU Z., MAO J. Crossing the "Environmental High Mountain" - On the rise and fall of environmental load in the process of economic growth.Engineering Science, 12, 36-42, 2003 [In Chinese]. 
18. LU Z., WANG H., YUE Q. Decoupling Index: Quantitative Expression of Resource Consumption, Waste Discharge and Economic Growth. Resources Science, 33 (01), 2, 2011 [In Chinese].

19. ZHU Y., LI L., HE S., LI H., WANG Y. Annual forecast of peak carbon emissions in Shanxi Province based on IPAT model and scenario analysis method.Resources Science, 38 (12), 2316, 2016 [In Chinese].

20. CHE, L., HAN X., ZHAO L.,WU C. China's coal utilization efficiency evaluation and analysis of its decoupling from economic growth. China Population - Resources and Environment, 25 (03), 104, 2015 [In Chinese].

21. WAN L., WANG Z. Measurement of Industrial Carbon Emission Decoupling Effect - Based on the Empirical Analysis of China's Equipment Manufacturing Industry. Science and Technology Management Research, 37 (03), 215, 2017 [In Chinese].

22. FAN R.G., WU Y. Study on carbon emissions and economic growth based on elasticity decoupling theory in china over 2000-2011. Applied Mechanics and Materials, 3013, 1853, 2014.

23. ZHOU J., GUANG F., GAO Y. Prediction of $\mathrm{CO}_{2}$ Emissions Based on the Analysis and Classification of Decoupling. Polish Journal of Environmental Studies, 26, 2851, 2017.

24. XU G., SONG D. Empirical Research on the Relationship between China's Export Trade, Economic Growth and
Carbon Emissions. International Trade Issues, 1, 74, 2010 [In Chinese].

25. BAI Y., ZHANG Y., WU X. Empirical Research on the Impact of Export Trade of Major Industrial Industries on Carbon Emissions. Industrial Technology and Economy, 33 (06), 26, 2014 [In Chinese].

26. LIU A., ZENG H., LIU W. An empirical study on the decoupling relationship between China's carbon emissions and export trade. China Population. Resources and Environment, 24 (07), 73, 2014 [In Chinese].

27. ZHAO K., YI X., LIU Y. Research on the Decoupling of China's Export Trade and Carbon Emissions. Journal of Wuhan University of Technology (Social Science Edition), 30 (04), 83, 2017 [In Chinese].

28. HU J., GAO P., ZHANG W. Research on the Decoupling Relationship between China's Foreign Trade Growth and embodied carbon Emissions. Management World, 10, 172, 2017 [In Chinese].

29. NAMINSE E. Y., ZHUANG J. Economic Growth, Energy Intensity, and Carbon Dioxide Emissions in China. Polish Journal of Environmental Studies, 27, 2193, 2018.

30. WEIJUAN LI, XIAO OUYANG Investigating the development efficiency of the green economy in China's equipment manufacturing industry. Environmental Science and Pollution Research, 27 (19), $24070,2020$. 